\title{
Estudo teórico e experimental de paredes esbeltas de alvenaria estrutural
}

\author{
Theoretical and experimental study of slender structural \\ masonry walls
}

\section{Guilherme Aris Parsekian \\ Márcio Roberto Silva Corrêa \\ Guilherme Martins Lopes Isabella Cavichiolli}

\section{Resumo}

$\mathbf{U}$

$\mathrm{m}$ dos fatores a serem levados em conta no dimensionamento de elementos comprimidos é sua esbeltez. Até hoje no Brasil utiliza-se o conceito de esbeltez simplificado, no qual o comprimento de flambagem é determinado por uma altura efetiva $\left(h_{\mathrm{ef}}\right)$, e o raio de giração é substituído por um parâmetro chamado espessura efetiva $\left(\mathrm{t}_{\mathrm{ef}}\right)$, para o cálculo de fator minorador de resistência. Outras normas de alvenaria estrutural, como as norte-americana, europeia e australiana, trazem também em sua formulação de cálculo da capacidade de carga de uma parede comprimida um fator redutor de resistência. Já a normalização canadense indica que seja feita uma análise mais próxima da realidade, considerando o equilíbrio na configuração deformada da parede (análise P-Delta). Um programa experimental que envolveu 18 ensaios de paredes de blocos cerâmicos e de concreto com elevada esbeltez, obtida com a utilização de blocos de pequena espessura, é aqui relatado. As previsões da capacidade de carga para o caso de blocos de concreto de geometria vazada foram próximas aos resultados dos ensaios. No caso dos blocos cerâmicos utilizados, de geometria complexa, com as paredes dos blocos também vazadas, apenas a aproximação da norma canadense permitiu obter com algum grau de segurança e proximidade os resultados dos ensaios. Paredes mais esbeltas e com blocos de geometrias complexas exigem procedimentos mais refinados para o cálculo, em que o processo P-Delta e a verificação da seção com material não resistente à tração podem ser uma solução.

Palavras-chaves: Alvenaria estrutural. Esbeltez. Compressão.

Guilherme Aris Parsekian Universidade Federal de São Carlos São Carlos - SP - Brasil

Márcio Roberto Silva Corrêa Universidade de São Paulo São Carlos - SP - Brasil

Guilherme Martins Lopes Morelli Lopes Engenharia Prado Jaú - SP - Brasil

Isabella Cavichiolli Universidade Federal de São Carlos São Carlos - SP - Brasil

Recebido em 25/05/15 Aceito em 22/05/16

\section{Abstract}

One of the factors to be taken into account in the design of compression loaded elements is their slenderness. Nowadays, in Brazil, the industry still uses the concept of simplified slenderness ratio - in which the buckling length is determined by an effective height $\left(h_{e f}\right)$ and the radius of gyration is replaced by a parameter called effective thickness $\left(t_{e f}\right)$ - when calculating the resistance reduction factor. Other masonry codes, such as the North American, European and Australian, also use the resistance reduction factor in their wall compression load capacity formulation. Yet, the Canadian code indicates the need for a more accurate and realistic analysis of slender walls, considering the balance in the deformed configuration of the wall ( $P$-Delta analysis). This paper reports the findings of an experimental program that tested 18 ceramic and concrete block walls with high slenderness ratios, obtained with thin block dimensions. The predictions of load capacity for the case of hollow concrete blocks were close to the test results. In the case of the ceramic blocks, which had a complex, double-face shell geometry, only the Canadian code approach produced the test results with some degree of certainty and proximity. Slenderer walls and complex geometry blocks require more refined calculation procedures. P-Delta analysis and the verification of the section with brittle-tensile materials solutions may apply.

Keywords: Structural masonry. Slenderness. Compression. 


\section{Introdução}

Desde a antiguidade a alvenaria vem sendo utilizada como estrutura em diversos tipos de edificações, e a literatura informa amplamente sobre o desenvolvimento histórico da alvenaria estrutural. Nos Estados Unidos da América (EUA), entre os anos de 1889 e 1891, é construído o edifício Monadnock, na cidade de Chicago, de 16 andares e cerca de 60 metros de altura, em que foram utilizados blocos cerâmicos, com paredes de espessuras que variavam de $30 \mathrm{~cm}$ no topo até cerca de $1,80 \mathrm{~m}$ na base.

Essas grandes espessuras de paredes se davam pelo fato de que o modelo de cálculo da época admitia que os esforços laterais do edifício deveriam ser integralmente absorvidos pelas paredes de fachada. Uma concepção comum era manter o alinhamento externo das paredes, variando-se a espessura a cada andar, o que fazia com que cada andar superior aplicasse suas cargas verticais nos andares inferiores com excentricidade. Limitando-se o deslocamento da parede superior sobre a inferior, o momento correspondente a essa excentricidade não era suficiente para tombar o edifício, mas apenas para equilibrar o momento gerado pelas ações laterais.

Avançando agora para a Europa do período pósSegunda Guerra Mundial, era necessária a construção de muitas edificações, por conta da destruição causada, com baixo custo e elevada rapidez, ou seja, racionalizadas.

Nessa época engenheiros avaliaram que o sistema de pórticos (pilares e vigas) poderia não ser econômico para edifícios residenciais que possuem diversas paredes de divisórias. Com isso se pensou em apoiar as lajes diretamente nas paredes e utilizar as paredes como estrutura. Porém era preciso avançar o conhecimento sobre a alvenaria como estrutura. A partir de pesquisas iniciadas nesse período surgiram novos materiais e procedimentos de cálculo.

Um exemplo marcante desse período são os edifícios construídos na Suíça, na década de 50, pelo engenheiro e professor Paul Haller. Um edifício composto de 18 andares foi construído em alvenaria não armada com paredes de espessura entre $30 \mathrm{~cm}$ e $37,5 \mathrm{~cm}$. Foi uma revolução no uso da alvenaria estrutural. Era pioneira a utilização de procedimentos racionais de dimensionamento, devendo-se, porém, ressaltar que isso só foi possível após estudos teóricos e experimentais, bem como sua correlação. Estima-se que o professor Paul Haller tenha ensaiado mais de 1.600 paredes de alvenaria para fundamentar seus trabalhos.
Atualmente no Brasil, com o grande desenvolvimento dos procedimentos de cálculo e dos materiais aplicados para alvenaria estrutural, têm sido construídos edifícios altos em que as paredes possuem espessura entre $14 \mathrm{~cm} \mathrm{e} 19 \mathrm{~cm}$, respeitando-se os limites de esbeltez impostos pelas normas brasileiras.

A normalização brasileira trata o problema de esbeltez/flambagem de paredes de alvenaria de forma muito simplificada, utilizando um coeficiente redutor de resistência à compressão em função da esbeltez do elemento estrutural. Esse fator tem sua origem em normas e códigos de construção internacionais bastante antigos, remontando a épocas em que esses documentos tratavam o dimensionamento pelo Método das Tensões Admissíveis, tendo sido perdida a efetiva explicação dessa dedução. Em consultas feitas a vários pesquisadores estrangeiros e de tradição no desenvolvimento de normas internacionais, sabe-se apenas que tal fator foi calibrado por meio de alguns ensaios experimentais, cujo registro hoje é desconhecido.

Com as diversas atualizações de normas internacionais em alvenaria estrutural e com a consequente adoção do Método dos Estados Limites para dimensionamento, esse fator foi modificado. Na normalização brasileira, mesmo com a adoção do Método dos Estados Limites, o fator original continua vigente, o que pode gerar contradição na atualização das normas brasileiras.

Estudos comparativos sobre o efeito da redução da resistência devida à esbeltez (PARSEKIAN, 2002; CORREA; SILVA, 2010) mostram que existem grandes diferenças nos resultados quando se compara o método simplificado na NBR com os de outras normas internacionais, especialmente para índices de esbeltez elevados.

Essas diferenças provavelmente não induzem à perda de segurança na maioria das estruturas nacionais porque o índice de esbeltez tem sido limitado a valores baixos, em especial no caso da alvenaria não armada. Porém, valores mais altos de esbeltez são comuns em depósitos, supermercados, shopping centers, ginásios de esportes, casas populares térreas com bloco de pequena espessura e em edificações residenciais com pé-direito duplo. A garantia de segurança dessas estruturas, sendo os cálculos realizados da forma usual, é, portanto, questionável.

Paredes muito esbeltas levam ao desenvolvimento de excentricidades adicionais devidas à deformação lateral em um efeito conhecido como $\mathrm{P} \cdot \Delta$. Mais recentemente foram desenvolvidos

198 Parsekian, G. A.; Corrêa, M. R. S.; Lopes, G. M.; Cavichiolli, I. 
procedimentos de cálculo em que esses efeitos são levados em conta de forma precisa, formulando-se o equilíbrio do elemento estrutural em sua configuração deformada.

Paredes relativamente curtas têm redução de resistência devida à esbeltez consideravelmente menor que paredes esbeltas. Por conta disso, devido à existência de limites de esbeltez rigorosos nos códigos de normas, poucos casos de paredes com problemas de flambagem são conhecidos. Esse é o caso da normalização brasileira, que limita a razão $\mathrm{h} / \mathrm{t}$ (altura /espessura) a um máximo de 30 para alvenaria armada e de 24 para a não armada. Isso leva a um dimensionamento simplificado, que se situa entre o procedimento empírico histórico e o da engenharia moderna.

Este trabalho envolve estudo dividido em duas partes (teórica e experimental), nas quais são analisadas especificações de normas e textos internacionais para dimensionamento de paredes de alvenaria esbeltas, sendo apresentados resultados de ensaios laboratoriais de paredes com esbeltez superior a 30 .

\section{Análise teórica}

A análise teórica aborda os critérios de dimensionamento à compressão simples de paredes de alvenaria. São estudadas as normas brasileiras NBR 15961-1 (ABNT, 2011a) e NBR 15812-1 (ABNT, 2010), a americana ACI 530 (AMERICAN..., 2013), a canadense CSA - S304.1 (CANADIAN..., 2004), a europeia BS EN 1996-11 (BRITISH..., 2005b) e a australiana AS 3700 (STANDARDS..., 2001). Ressalva-se que os textos de ambas as normas brasileiras são idênticos para o caso do dimensionamento à compressão. Neste texto, será citada a seguir apenas a NBR 15961-1 (ABNT, 2011a), uma vez que não haveria diferença de dimensionamento com a adoção da NBR 15812-1 (ABNT, 2010).

\section{Altura efetiva}

A altura efetiva de uma parede é determinada pelo produto de sua altura livre por um fator dependente de suas vinculações. É o equivalente ao comprimento de flambagem. A Tabela 1, adaptada das normas citadas, apresenta um resumo do cálculo da altura efetiva de paredes de alvenaria estrutural. As condições de travamento lateral consideradas são Laje x Laje (parede com lajes na base e no topo) e Laje x Livre (parede com apoio em laje apenas em sua base).

\section{Espessura efetiva}

A espessura efetiva de uma parede tem relação com seu raio de giração. Em algumas normas o raio de giração é considerado diretamente. Em outras se define a espessura efetiva como a espessura de uma parede simples. Para uma parede com enrijecedores, a espessura efetiva será a equivalente a uma parede simples com raio de giração semelhante à seção da parede com enrijecedor. Em muitas normas a espessura efetiva pode ser determinada por um fator multiplicador da espessura da parede simples para considerar a presença do enrijecedor, conforme a Tabela 2.

\section{Índice de esbeltez}

A razão de esbeltez indica a importância do problema de flambagem no elemento estrutural. Paredes com índice de esbeltez pequenos (robustas) têm o limite de resistência à compressão governado pela simples resistência à compressão do material estimada por corpos de prova curtos (a flambagem não é relevante). De maneira análoga, em paredes esbeltas a questão de deslocamentos laterais e consequentes esforços de segunda ordem limitam a resistência a um valor inferior à resistência à compressão simples do material. Para as normas brasileira NBR 15961-1 (ABNT, 2011a), canadense CSA S304.1 (CANADIAN..., 2004), europeia BS EN 1996-1-1 (BRITISH..., 2005b) e australiana AS 3700 (STANDARDS..., 2001), o índice de esbeltez é dado pela razão entre a altura efetiva $\left(h_{e}\right)$ e a espessura efetiva $\left(t_{e}\right)$.

Tabela 1 - Coeficientes para altura efetiva (fator da altura livre)

\begin{tabular}{c|c|c}
\hline Norma & Laje x Laje & Laje x Livre \\
\hline NBR 15961-1 (ABNT, 2011a) & 1,00 & 2,00 \\
ACI 530 (AMERICAN..., 2013) & 1,00 & 2,00 \\
CSA S304.1 (CANADIAN..., 2004) & 0,75 & $2,00 *$ \\
BS EN 1996-1-1 (BRITISH..., 2005b)* & 0,80 & 2,00 \\
AS 3700 (STANDARDS..., 2001) & 0,75 & 2,50 \\
\hline
\end{tabular}

Nota: *valor retirado da norma inglesa BS 5628-1 (BRITISH..., 2005a). 
Tabela 2 - Coeficientes para o cálculo de espessura efetiva

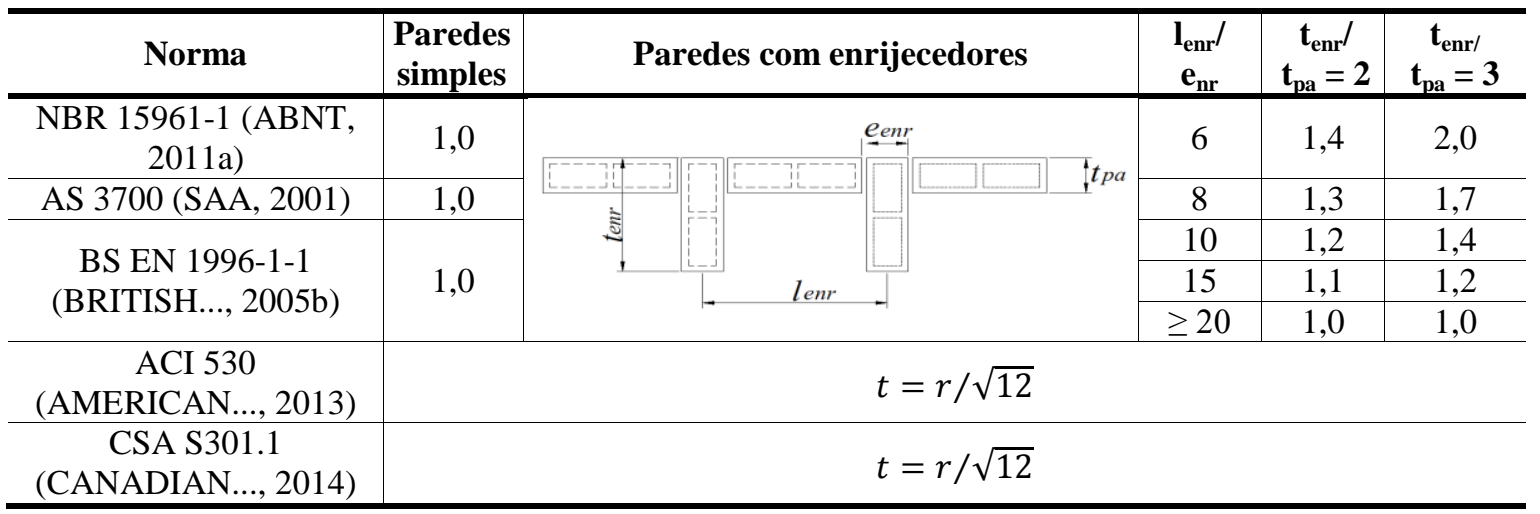

O índice de esbeltez na norma brasileira NBR 15961-1 (ABNT, 2011a) está limitado em 24 para alvenaria não armada e em 30 para alvenaria armada; na norma canadense CSA S304.1 (CANADIAN..., 2004) está limitado em 30 para ambas; para a norma europeia BS EN 1996-1-1 (BRITISH..., 2005b) está limitado em 27 também para ambas. Para a norma americana ACI 530 (AMERICAN..., 2013) o índice de esbeltez é a razão entre a altura efetiva $\left(h_{e}\right)$ e o raio de giração da parede (r). Deve-se destacar que devido às simplificações de cada norma o mesmo "índice de esbeltez" pode levar a paredes com diferentes esbeltezes reais. Como a condição laje-laje é entendida com altura efetiva 1,0 na normalização brasileira e 0,75 na normalização europeia, a "esbeltez" 20 europeia equivale à "esbeltez" 15 brasileira.

\section{Dimensionamento à compressão simples}

A resistência à compressão é propriedade determinante no uso de paredes como estrutura, uma vez que a grande maioria dos elementos estruturais nesse tipo de sistema construtivo é submetida preponderantemente ao esforço de compressão.

\section{Norma brasileira NBR 15961-1}

Para a norma brasileira NBR 15961-1 (ABNT, 2011a), o dimensionamento à compressão simples de paredes não armadas é apresentado a seguir. Observa-se que a referida norma recomenda a desconsideração de eventuais armaduras comprimidas. Deve-se destacar que, para considerar a contribuição da armadura comprimida, essa deve estar corretamente contraventada. Uma solução comum em concreto armado é a inclusão de estribos com espaçamento adequado, o que não é o caso usual de construções em alvenaria no Brasil, assim como não é o caso do detalhe das paredes ensaiadas (Eq. 1).

$\frac{\gamma_{f} \cdot P_{k}}{A} \leq\left\{\begin{array}{c}1,0 \text { paredes } \\ 0,9 \text { pilares }\end{array}\right\} \cdot \frac{0,7 f_{p k}}{\gamma_{m}} \cdot\left[1-\left(\frac{h_{e f}}{40 t_{e f}}\right)^{3}\right]$ Eq. 1

Onde:

$P_{k}$ : força normal atuante $(\mathrm{kN})$;

$\mathrm{f}_{\mathrm{pk}}$ : resistência à compressão característica do prisma $\left(\mathrm{kN} / \mathrm{m}^{2}\right)$;

$\gamma_{\mathrm{m}}$ : coeficiente de segurança da alvenaria $\left(\gamma_{m}=\right.$ 2,0), combinação normal;

$\gamma_{\mathrm{f}}$ : coeficiente majorador das ações $\left(\gamma_{f}=1,40\right)$, combinação normal;

$\mathrm{h}_{\mathrm{ef}}$ : altura efetiva $(\mathrm{m})$; e

$\mathrm{t}_{\mathrm{ef}}$ : espessura efetiva $(\mathrm{m})$.

\section{Norma americana ACI 530}

Pelo mesmo motivo do item anterior, considera-se aqui apenas o dimensionamento de paredes não armadas de acordo com ACI 530 (AMERICAN..., 2013) (Eq. 2 e 3):

$P_{d}=0,80\left\{0,80 A_{n} f_{m}^{\prime}\left[1-\left(\frac{h}{140 r}\right)^{2}\right]\right\}$ para $h / r \leq 99$

Eq. 2

$P_{d}=0,80\left[0,80 A_{n} f_{m}^{\prime}\left(\frac{70 r}{h}\right)^{2}\right]$ para $h / r>99$ Eq. 3

Onde:

$A_{n}$ : área efetiva de argamassa $\left(\mathrm{m}^{2}\right) ;$

$f_{m}^{\prime}$ : resistência à compressão do prisma $\left(\mathrm{kN} / \mathrm{m}^{2}\right)$;

$h$ : altura efetiva da parede (m); e

$r$ : raio de giração $(\mathrm{m})$.

\section{Norma canadense CSA S301.1}

Para a norma canadense CSA S304.1 (CANADIAN..., 2004), o efeito da esbeltez pode ser considerado levando-se em conta o efeito da 
curvatura $(\mathrm{P} \cdot \Delta)$, conforme item seguinte deste texto. $\mathrm{Na}$ combinação com eventual flexão decorrente de força lateral, o efeito dessa flexão somada ao efeito da esbeltez pode ser aproximado por um coeficiente majorador do momento atuante. O método está descrito em Parsekian, Hamid e Drysdale (2013). Considere-se uma parede simplesmente apoiada na base e no topo, com um carregamento de projeto, $\mathrm{P}_{\mathrm{d}}$, excêntrico, conforme a Figura 1a. Admite-se que a linha elástica do elemento tem a forma de uma senoide, sendo $\Delta_{0} \mathrm{o}$ deslocamento devido ao momento de primeira ordem, $\mathrm{M}_{\mathrm{d}}=\mathrm{P}_{\mathrm{d}} \mathrm{e}$. $\mathrm{O}$ momento de segunda ordem, ocasionado pela deflexão da parede, irá causar o incremento de deslocamento $\Delta_{1}$ (deslocamento de segunda ordem).

A partir da resolução da equação da linha elástica, chega-se a (Eq. 4):

$\Delta_{1}=\left(\frac{P_{d}}{E I}\left(\Delta_{0}+\Delta_{1}\right) \frac{h}{2} \times \frac{2}{\pi}\right) \frac{h}{\pi}=\frac{P_{d} h^{2}}{\pi^{2} E I}\left(\Delta_{0}+\Delta_{1}\right)$ Eq. 4

Considerando a carga crítica de Euler, $\mathrm{P}_{\mathrm{cr}}=\frac{\pi^{2} E I}{h^{2}}$, e substituindo e rearranjando a equação 4 , chega-se ao deslocamento total, obtido de forma incremental, igual a (Eq. 5):

$$
\begin{aligned}
& \Delta_{T}=\Delta_{0}+\Delta_{0}\left(\frac{{ }^{P} d / P_{c r}}{1-{ }^{P} d / P_{c r}}\right)= \\
& \Delta_{0}\left(\frac{1-{ }^{P} d / P_{c r}+{ }^{P} d / P_{c r}}{1-{ }^{P} d / P_{c r}}\right)=\frac{\Delta_{0}}{1-{ }^{P} d / P_{c r}}
\end{aligned}
$$

O deslocamento lateral, $\Delta_{T}$, cresce com o aumento da carga aplicada, $\mathrm{P}_{\mathrm{d}}$. Então, o momento máximo (total) será igual a (Eq. 6):

$M_{d, \text { total }}=P_{d} e+P_{d} \Delta_{T}=P_{d} e+\frac{P_{d} \Delta_{0}}{1-{ }^{P} d / P_{c r}} \quad$ Eq. 6

Para um momento fletor constante igual a $P_{d} e$, tem-se (Eq. 7):

$\Delta_{0}=\frac{P_{d} e h^{2}}{8 E I}$

Então, chega-se a (Eq. 8):

$$
\begin{aligned}
& M_{d, \text { total }}=P_{d} e+\frac{P_{d}}{{ }^{1-P_{d} / P_{c r}}} \frac{P_{d} e h^{2}}{8 E I}=P_{d} e+\frac{P_{d}}{\left(1{ }^{P} d / P_{c r}\right)} \frac{P_{d} e^{\pi^{2}} / 8}{P_{c r}}= \\
& =P_{d} e \frac{\left(1+0,23{ }^{P} / P_{c r}\right)}{1{ }^{P} d / P_{c r}}
\end{aligned}
$$

O termo 0,23 $P_{-} d / P_{-} c r$ é considerado não relevante e descartado da equação (só é relevante em paredes curtas, sendo desprezado para o cálculo de carga limite de paredes esbeltas) (Eq. 9).

$$
M_{d, \text { total }}=M_{d} \frac{1}{1-{ }^{P} d / P_{c r}}
$$

Eq. 9

Figura 1 - Método do coeficiente amplificador de momento

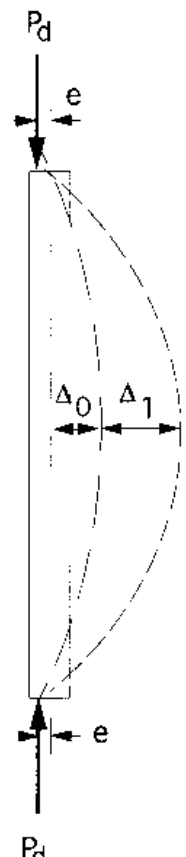

$P_{d}$

(a) Força e

deslocamentos

(b) Momento

de 1a ordem

\section{$P_{d e}$}

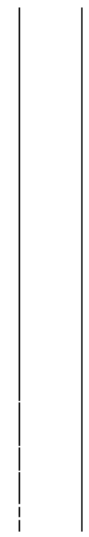

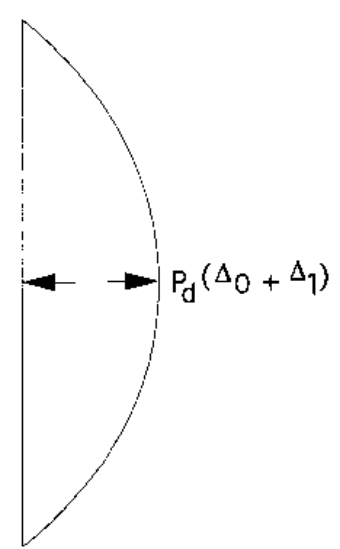

(c) Momento de $2 \mathrm{a}$ ordem

Fonte: Parsekian, Hamid e Drysdale (2013). 
Entretanto, a equação como deduzida é aplicável apenas em diagramas simétricos, com mesma excentricidade na base $\left(e_{2}\right)$ e no topo $\left(e_{1}\right)$. Quando o valor de $e_{2}$ é maior que $e_{1}$, um fator de equivalência $C_{m}$ (Eq. 11), deduzido originalmente para dimensionamento de estruturas de aço, deve ser incluído (Eq. 10):

$M_{d, \text { total }}=M_{d} \frac{C_{m}}{1-{ }^{P} d / P_{c r}}$,

Eq. 10

Onde o termo $\frac{C_{m}}{{ }_{1-}{ }^{P} / P_{c r}}$ é chamado de coeficiente amplificador de momento.

$C_{m}=0,6+0,4 \frac{M_{1}}{M_{2}}=0,6+0,4 \frac{e_{1}}{e_{2}} \geq 0,4$

A fissuração da alvenaria, a consideração da não linearidade da relação tensão-deformação da alvenaria e o escoamento do aço são fatores que influenciam o cálculo da rigidez da alvenaria (EI), tornando muito difícil estimar um valor preciso para essa grandeza por um método simples. Para simplificar e permitir a análise do elemento, um valor de EI reduzido, para levar em conta esses efeitos, é especificado, sendo a rigidez reduzida chamada de "efetiva", $\mathrm{EI}_{\mathrm{ef}}$, podendo ser estimada por:

$E I_{e f}=0,4 E_{a} I_{0} \rightarrow$ para alvenaria não armada

$E I_{e f}=E_{a}\left[0,25 I_{0}-\left(0,25 I_{0}-I_{c r}\right)\left(\frac{e-e_{k}}{2 e_{k}}\right)\right] \rightarrow$ para alvenaria armada,

Onde:

$E_{a}=$ módulo de elasticidade da alvenaria $\left(800 \mathrm{f}_{\mathrm{pk}}\right.$ para blocos de concreto ou $600 \mathrm{f}_{\mathrm{pk}}$ para blocos cerâmicos);

$I_{0}=$ momento de inércia da seção não fissurada (área efetiva para alvenaria não armada, área equivalente para alvenaria armada); w

$e_{k}=$ excetricidade para início da fissuração por tração (relação W/A da seção não fissurada).

No caso de alvenaria armada $E_{\text {ef }}$, não deve ser tomado maior que $0,25 E_{a} I_{0}$, nem menor que $E_{a} I_{c r}$ ( $\mathrm{I}_{\mathrm{cr}}$ é o momento de inércia da seção fissurada).

Ainda, para levar em conta as deformações lentas ao longo do tempo, o valor de $\mathrm{E}_{\text {ef }}$ deve ser dividido por $\left(1-0,5 \beta_{\mathrm{d}}\right)$, onde $\beta_{\mathrm{d}}$ é a razão entre o momento devido à ação permanente e o momento devido à ação total. Deve-se destacar que o valor de $\beta_{\mathrm{d}}$ é aqui calculado em função do momento, e não da carga força normal, como seria adotado para seções de concreto armado. O coeficiente 0,5 é utilizado para estimar efeitos de retração e fluência, e esse valor leva a reduções de rigidez menores do que seria usualmente adotado para seções de concreto armado. Para a determinação do valor de projeto de carga crítica, deve-se ainda incluir o coeficiente redutor da resistência da alvenaria, $\gamma_{\mathrm{m}}$, usualmente especificada como 2,0. A carga crítica de flambagem (Euler), $\mathrm{P}_{\mathrm{cr}}$, pode então ser obtida por (Eq. 12):

$P_{c r}=\frac{\pi^{2}(E I)_{e f}}{(k h)^{2}\left(1+0,5 \beta_{d}\right) \gamma_{m}}$

Recentemente, na versão de 2014, a norma CSA S304.1 inclui recomendações específicas para paredes muito esbeltas, com índice de esbeltez superior a 30:

(a) as paredes devem ser armadas;

(b) a espessura dos blocos deve ser no mínimo igual a $140 \mathrm{~mm}$;

(c) deve-se assumir a condição das extremidades como simplesmente apoiadas;

(d) a carga máxima aplicada não deve corresponder a mais do que $10 \%$ da resistência de prisma, com valores de projeto para a solicitação e a resistência;

(e) a máxima área de armadura deve levar à posição relativa da linha neutra da seção, $\mathrm{x} / \mathrm{d} \leq 600$ / $\left(600+\mathrm{f}_{\mathrm{y}}\right)$; e

(f) deve-se obrigatoriamente dimensionar a parede levando-se em conta os efeitos $P \cdot \delta$.

\section{Norma europeia BS EN 1996-1-1}

A norma europeia BS EN 1996-1-1 (BRITISH..., 2005b) apresenta o procedimento descrito abaixo para o dimensionamento à compressão em paredes não armadas. Essa norma permite estimar a resistência da parede em função da resistência do bloco e da argamassa com parâmetros variáveis em função do material e da geometria da alvenaria. Neste artigo apresenta-se apenas a parte relativa à redução devida à esbeltez e à excentricidade.

No estado limite último, o valor de cálculo da força normal aplicada a paredes de alvenaria, $\mathrm{N}_{\mathrm{Sd}}$, deve ser inferior ou igual ao valor de projeto de resistência à compressão da parede, $\mathrm{N}_{\mathrm{Rd}}$, de tal forma que (Eq. 13):

$N_{S d} \leq N_{R d}=\phi t f_{d}$

Eq. 13

Onde:

$\phi$ : fator de redução de capacidade;

$t$ : espessura da parede (m); e

$f_{d}$ : resistência à compressão de projeto da alvenaria $\left(\mathrm{kN} / \mathrm{m}^{2}\right)$.

$\mathrm{O}$ valor do fator de redução $\phi$ a ser utilizado deve ser o menor entre o redutor do topo da parede e da base $\left(\phi_{\mathrm{i}}\right)$, Eq. 14 e 15, e o redutor do meio da parede $\left(\phi_{\mathrm{m}}\right)$. 
$\phi_{i}=1-2 \frac{e_{i}}{t}$

Eq. 14

Onde:

$t$ : espessura da parede $(\mathrm{m})$; e

$e_{i}$ : excentricidade na parte superior ou inferior da parede,

$e_{i}=\frac{M_{i d}}{N_{i d}}+e_{h i}+e_{a} \geq 0,05 t_{e f}$

Onde:

$M_{i d}$ : valor de projeto do momento fletor na parte superior ou inferior da parede, resultando da excentricidade de carga do piso no apoio (kN.m);

$N_{i d}$ : valor de projeto da carga vertical na parte superior ou inferior da parede $(\mathrm{kN})$;

$e_{h i}$ : excentricidade na parte superior ou inferior da parede $(\mathrm{m})$;

$e_{a}$ : excentricidade acidental $(\mathrm{m}) ; \mathrm{e}$

$t_{e f}$ : espessura efetiva da parede (m).

Para o meio da parede, o redutor $\left(\phi_{\mathrm{m}}\right)$ é dado por (Eq. 16, 17 e 18):

$\emptyset_{m}=\left(1-2 \frac{e_{m k}}{t}\right) e^{-\frac{u^{2}}{2}}$

Com,

$u=\frac{\frac{h_{e f}}{t_{e f}}-2}{23-37 \frac{e_{m k}}{t}}$ (considerando de forma aproximada

$\mathrm{Ea}=700 \mathrm{fp})$

Eq. 17

$\mathrm{Ou}$

$u=\frac{\frac{h_{e f}}{t_{e f}} \sqrt{f_{k / E_{a}}}-0,063}{0,73-1,17 \frac{e_{m k}}{t}}$ (para qualquer valor de $\mathrm{E}_{\mathrm{a}}$ considerado)

Eq. 18

Onde:

$e_{m k}$ : excentricidade no meio de um quinto da altura da parede $(\mathrm{m})$;

$h_{e f}$ altura efetiva da parede (m);

$t_{e f}$ : espessura efetiva da parede $(\mathrm{m})$; e

$t$ : espessura da parede $(\mathrm{m})$.

$\mathrm{O}$ valor da excentricidade no meio de um quinto da altura da parede $\left(\mathrm{e}_{\mathrm{mk}}\right)$ é dado por (Eq. 19 e 20):

$e_{m k}=e_{m}+e_{k} \geq 0,05 t_{e f}$

$e_{m}=\frac{M_{m d}}{N_{m d}}+e_{h m} \pm e_{a}$

Eq. 20

Onde:

$e_{m}$ : excentricidade devida ao carregamento (m);

$M_{m d}$ : valor de projeto do maior momento no meio da altura da parede (kN.m);
$N_{m d}:$ valor de projeto da força normal no meio da altura da parede $(\mathrm{kN})$;

$e_{h m}$ : excentricidade a meia altura, resultante de cargas horizontais (por exemplo, vento) (m);

$h_{e f}$ : altura efetiva da parede (m);

$t_{e f}$ : espessura efetiva da parede $(\mathrm{m}) ; \mathrm{e}$

$e_{k}$ : excentricidade devida à fluência, calculada segundo a Equação 21:

$e_{k}=0,002 \phi_{\infty} \frac{h_{e f}}{t_{e f}} \sqrt{t e_{m}}$

$\phi_{\infty}$ : coeficiente de fluência final, para concreto $\phi_{\infty}$ entre 1,0 e 2,0 .

\section{Norma australiana AS 3700}

A norma australiana AS 3700 (STANDARDS..., 2001) apresenta o procedimento descrito abaixo para o dimensionamento a compressão de paredes não grauteadas (Eq. 22).

$F_{d} \leq k \emptyset f^{\prime}{ }_{m} A_{b}$

Eq. 22

Onde:

$F_{d}$ : força normal de compressão de cálculo $(\mathrm{kN})$;

$k=$ coeficiente redutor devido à esbeltez, dado pelo menor valor entre 0,67 e $0,67-0,02\left(\lambda_{r s}-\right.$ 14);

$\lambda_{r s}$ : coeficiente de esbeltez simplificado, tomado como a relação $h / t$ para o caso de paredes simplesmente apoiadas na base e no topo;

$\emptyset$ : coeficiente redutor de resistência à compressão $(\emptyset=0,45)$;

$f_{m}^{\prime}$ : resistência à compressão característica da parede $\left(\mathrm{kN} / \mathrm{m}^{2}\right)$; e

$A_{b}$ : área efetiva da seção transversal da parede $\left(\mathrm{m}^{2}\right)$.

\section{Análise experimental}

O programa experimental compreendeu a realização de ensaios de paredes sujeitas à compressão simples, com instrumentação instalada para a medida das deformações axiais e dos deslocamentos laterais em diferentes níveis ao longo de sua altura. Foram ensaiadas paredes não armadas de blocos de concreto e cerâmicos com $1,0 \mathrm{~m}$ de altura (5 fiadas) e $2,80 \mathrm{~m}$ de altura (14 fiadas), e paredes armadas também com 2,80 $\mathrm{m}$ de altura, num total de 18 ensaios de paredes. 


\section{Caracterização da argamassa, bloco, graute, prisma e pequena parede}

Os materiais utilizados, suas especificações e os resultados da caracterização estão indicados na Tabela 3. A argamassa para blocos cerâmicos foi utilizada com traço em volume 1,0 : 2,5:4,5 - a/c : 1,5, sendo o traço para blocos de concreto 1,0 : $2,0: 2,5-\mathrm{a} / \mathrm{c}: 0,95$. O traço do graute, também em volume, foi $1,0: 0,1: 1,4: 1,6-\mathrm{a} / \mathrm{c}: 0,60$, com $1,5 \%$ de aditivo compensador de retração. Mais detalhes da caracterização e dos ensaios podem ser verificados em Lopes (2014).

Desenhando os blocos de acordo com as medidas médias obtidas nas medições dos ensaios dimensionais, obtêm-se os valores descritos na Tabela 4. A Tabela 5 e 7 indicam os resultados dos ensaios de bloco, argamassa, graute, prisma oco, prisma grauteado e pequenas paredes.

\section{Ensaio de paredes esbeltas}

Foram moldadas 12 paredes com altura igual a 2,80 m (14 fiadas), sendo divididas em quatro grupos: CPI blocos de concreto sem armadura; CPII blocos cerâmicos sem armadura; CPIII blocos de concreto com armadura; e CPIV blocos cerâmicos com armadura (Figura 2). Nas paredes com armadura foram utilizadas duas barras com diâmetro de $12,5 \mathrm{~mm}$, dispostas de acordo com a Figura 3. As paredes foram construídas sobre uma base metálica. Nos ensaios essa base com a parede era colocada sobre uma faixa de neoprene com 2 $\mathrm{cm}$ de largura; esta, por sua vez, sobre uma viga metálica (Figura 4 e Figura 5). Dessa forma, o ensaio reproduz de forma rigorosa a condição de articulação na base e no topo. Deve-se destacar que essa condição é mais rigorosa que a condição de ensaio preconizada na NBR 14321 (ABNT, 1999) e que a condição usual de construções, em que usualmente a base e o topo são apoiados diretamente sobre bases largas (laje no caso da construção, chapa metálica no caso de ensaios usuais de parede). A instrumentação foi composta de uma série de transdutores (Figura 6) posicionados conforme a Figura 7. As paredes tiveram onze pontos de medição de deslocamentos horizontais, sendo três linhas de instrumentação: uma central com cinco pontos, e duas laterais com três pontos cada uma. Um exemplo dos deslocamentos medidos em parede do grupo CPII é mostrado na Figura 8. Esses deslocamentos seguem a curvatura esperada para o problema. O resumo dos resultados é indicado na Tabela 6.

Tabela 3 - Procedimentos utilizados na caracterização do bloco e parede

\begin{tabular}{c|c|c}
\hline & Ensaio & Procedimento \\
\hline \multirow{2}{*}{ BLOCO } & $\begin{array}{c}\text { Dimensional, absorção, resistência à } \\
\text { compressão, área líquida }\end{array}$ & $\begin{array}{c}\text { NBR 15270-3 (ABNT, 2005) e NBR } \\
12118(\mathrm{ABNT}, 2010)\end{array}$ \\
\hline PAREDE & Compressão de prisma & NBR 15961-2 (ABNT, 2011b) \\
\hline PAREDE & Compressão de pequena parede & NBR 15961-2 (ABNT, 2011b) \\
\hline PAREDE & Compressão de parede & NBR 8949 (ABNT, 1985) \\
\hline ARGAMASSA & Resistência à compressão & NBR 15961-2 (ABNT, 2011b) \\
\hline GRAUTE & Resistência à compressão & NBR 5738 (ABNT, 2008) e 5739 \\
& & (ABNT, 2007) \\
\hline
\end{tabular}

Tabela 4 - Resumo dos ensaios dimensionais

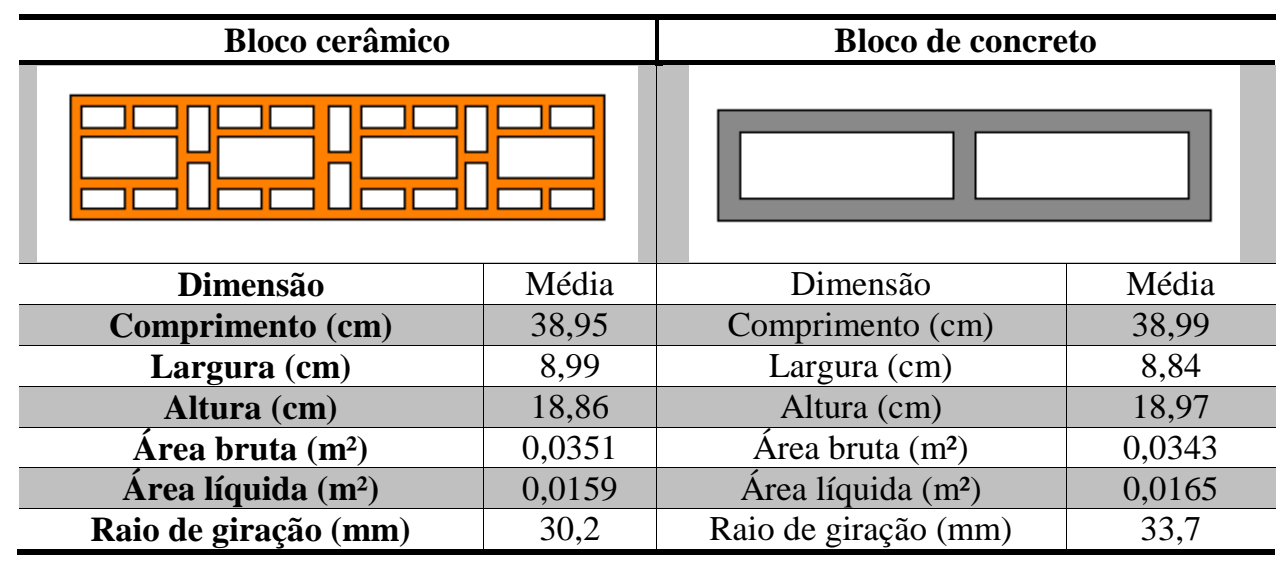

204 Parsekian, G. A.; Corrêa, M. R. S.; Lopes, G. M.; Cavichiolli, I. 
Tabela 5 - Resistências à compressão

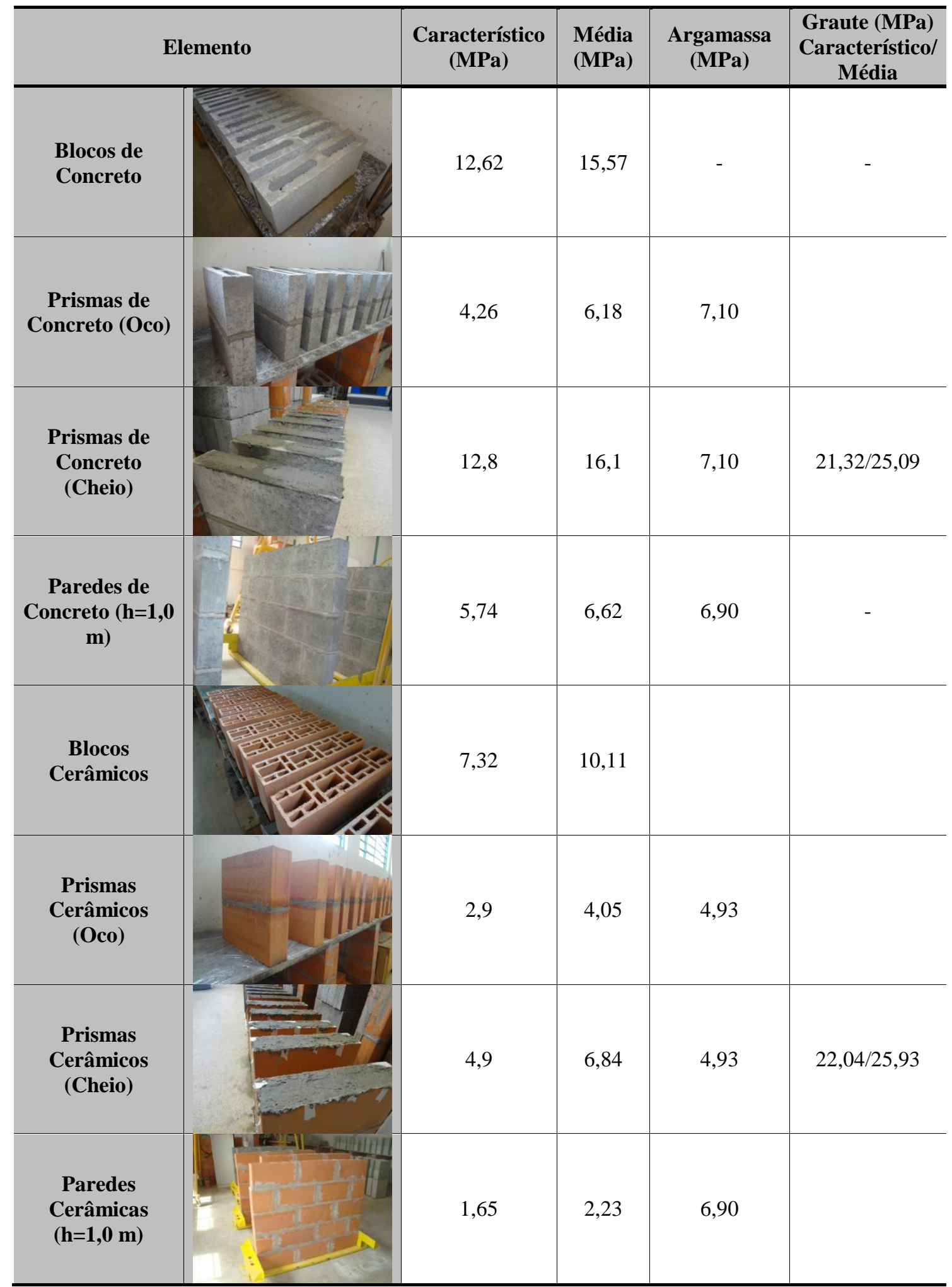


Figura 2 - Disposição das paredes

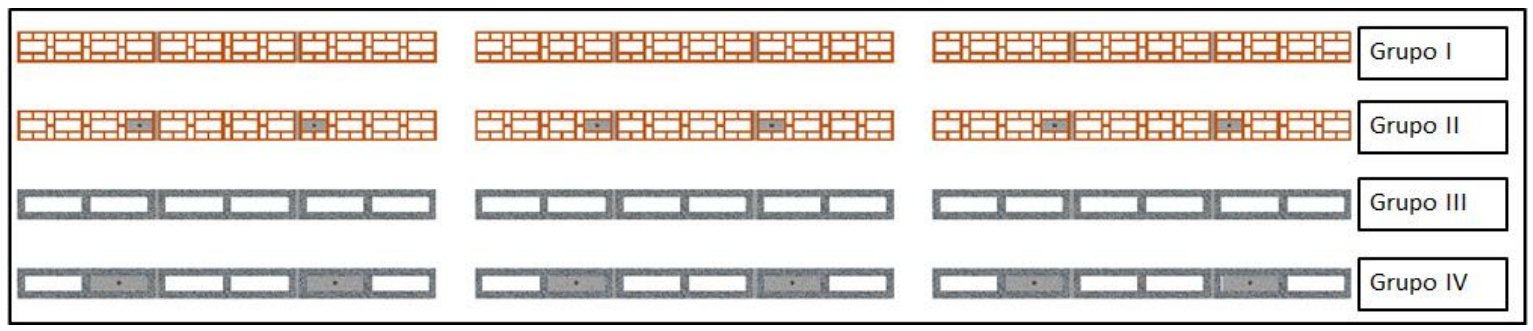

Figura 3 - Armação adotada nas paredes alterar a ordem de citacao

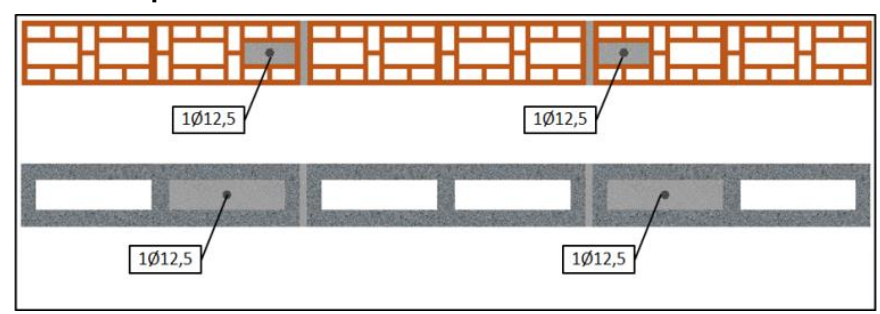

Figura 4 - Parede posicionada no pórtico de reação

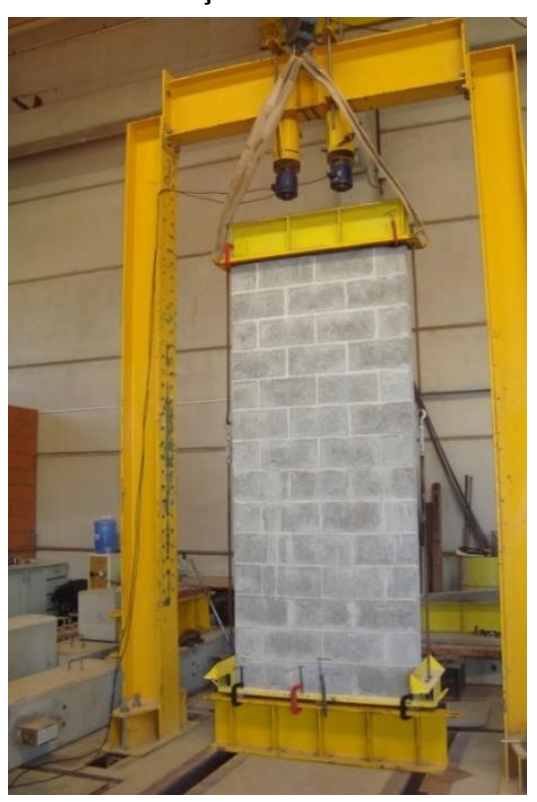

Figura 5 - Sistema de rótula inferior

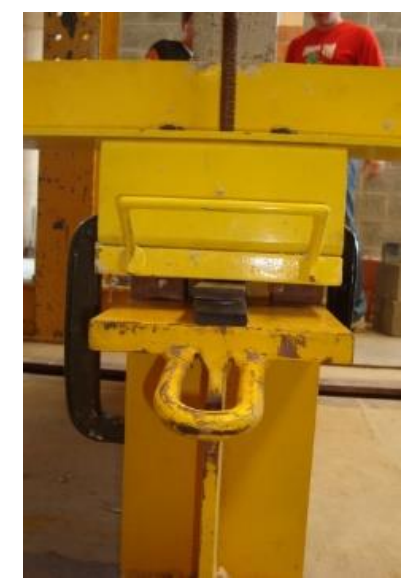

206 Parsekian, G. A.; Corrêa, M. R. S.; Lopes, G. M.; Cavichiolli, I. 
Figura 6 - Transdutor vertical

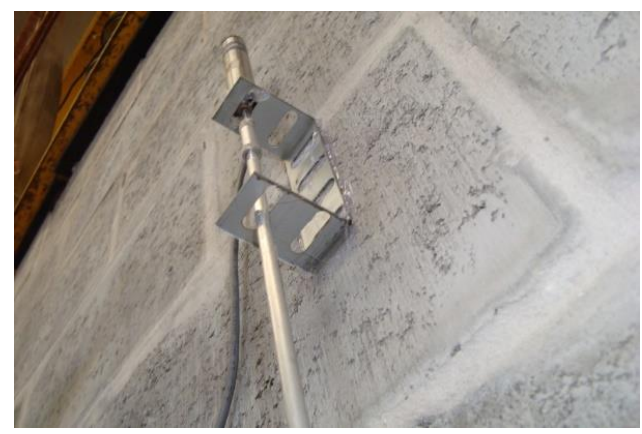

Figura 7 - Posição dos transdutores

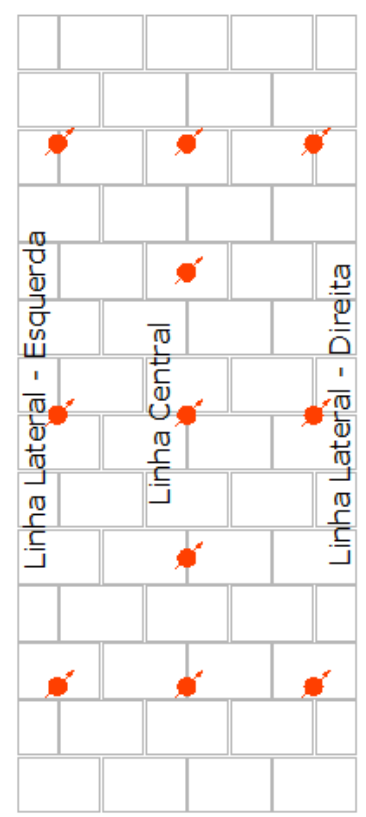

Figura 8 - Deslocamentos laterais CPII (mm)

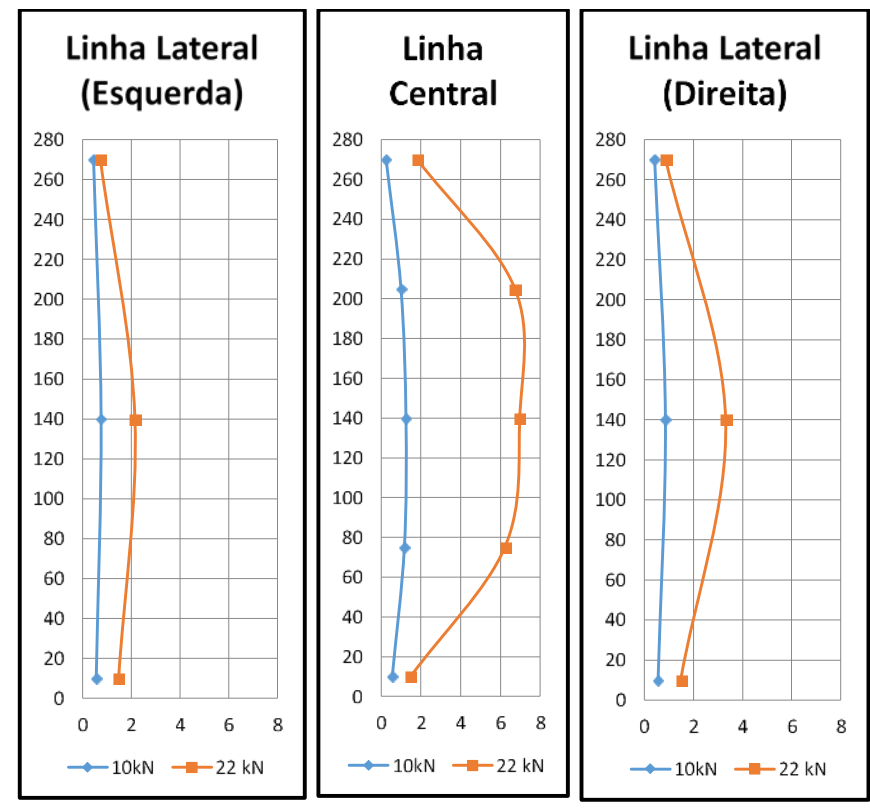


Tabela 6 - Resumo de resultados para paredes esbeltas

\begin{tabular}{|c|c|c|c|c|c|c|}
\hline Elemento & $\begin{array}{l}\text { Média } \\
\text { (MPa) }\end{array}$ & $\begin{array}{c}\text { Ep } \\
(\mathbf{G P a})\end{array}$ & \multicolumn{2}{|c|}{$\begin{array}{l}\text { Argamassa (MPa) - } \\
\text { Até } 7^{\mathrm{a}} \text { Fiada }\end{array}$} & \multicolumn{2}{|c|}{$\begin{array}{c}\text { Graute (MPa) - Até } 7^{\text {a }} \\
\text { Fiada }\end{array}$} \\
\hline \multirow[t]{5}{*}{$\begin{array}{c}\text { Blocos de Concreto - Não } \\
\text { Armadas }\end{array}$} & \multirow{5}{*}{0,24} & \multirow{5}{*}{0,25} & $\begin{array}{l}\text { Flexão } \\
(\mathrm{MPa})\end{array}$ & $\begin{array}{c}\text { Compressão } \\
(\mathrm{MPa})\end{array}$ & $\begin{array}{l}\text { Característico } \\
\text { (MPa) }\end{array}$ & $\begin{array}{l}\text { Média } \\
(\mathrm{MPa})\end{array}$ \\
\hline & & & 2,81 & 7,00 & - & - \\
\hline & & & \multicolumn{2}{|c|}{$\begin{array}{c}\text { Argamassa (MPa) - Até } \\
14^{\mathrm{a}} \text { Fiada }\end{array}$} & \multicolumn{2}{|c|}{$\begin{array}{c}\text { Graute (MPa) - Até } 14^{a} \\
\text { Fiada }\end{array}$} \\
\hline & & & $\begin{array}{l}\text { Flexão } \\
(\mathrm{MPa})\end{array}$ & $\begin{array}{c}\text { Compressão } \\
(\mathrm{MPa})\end{array}$ & $\begin{array}{l}\text { Característico } \\
\text { (MPa) }\end{array}$ & $\begin{array}{l}\text { Média } \\
(\mathrm{MPa})\end{array}$ \\
\hline & & & 2,64 & 6,27 & - & - \\
\hline Elemento & $\begin{array}{l}\text { Média } \\
\text { (MPa) }\end{array}$ & $\begin{array}{c}\text { Ep } \\
(\mathrm{GPa})\end{array}$ & \multicolumn{2}{|c|}{$\begin{array}{c}\text { Argamassa (MPa) - Até } \\
7^{\mathrm{a}} \text { Fiada }\end{array}$} & \multicolumn{2}{|c|}{$\begin{array}{c}\text { Graute (MPa) - Até } 7^{\mathrm{a}} \\
\text { Fiada }\end{array}$} \\
\hline \multirow[t]{5}{*}{$\begin{array}{c}\text { Blocos Cerâmicos - Não } \\
\text { Armadas }\end{array}$} & \multirow{5}{*}{0,05} & \multirow{5}{*}{0,29} & $\begin{array}{r}\text { Flexão } \\
(\mathrm{MPa})\end{array}$ & $\begin{array}{c}\text { Compressão } \\
(\mathrm{MPa})\end{array}$ & $\begin{array}{l}\text { Característico } \\
\text { (MPa) }\end{array}$ & $\begin{array}{l}\text { Média } \\
(\mathrm{MPa})\end{array}$ \\
\hline & & & 2,81 & 6,22 & - & - \\
\hline & & & \multicolumn{2}{|c|}{$\begin{array}{c}\text { Argamassa (MPa) - Até } \\
14^{\mathrm{a}} \text { Fiada }\end{array}$} & \multicolumn{2}{|c|}{$\begin{array}{c}\text { Graute (MPa) - Até } 14^{\mathrm{a}} \\
\text { Fiada }\end{array}$} \\
\hline & & & $\begin{array}{l}\text { Flexão } \\
(\mathrm{MPa})\end{array}$ & $\begin{array}{l}\text { Compressão } \\
(\mathrm{MPa})\end{array}$ & $\begin{array}{l}\text { Característico } \\
\text { (MPa) }\end{array}$ & $\begin{array}{l}\text { Média } \\
(\mathrm{MPa})\end{array}$ \\
\hline & & & 2,86 & 6,77 & - & - \\
\hline Elemento & $\begin{array}{l}\text { Média } \\
\text { (MPa) }\end{array}$ & $\begin{array}{l}\text { Ep } \\
(\mathrm{GPa})\end{array}$ & \multicolumn{2}{|c|}{$\begin{array}{c}\text { Argamassa (MPa) - Até } \\
7^{\mathrm{a}} \text { Fiada }\end{array}$} & \multicolumn{2}{|c|}{$\begin{array}{c}\text { Graute (MPa) - Até } 7^{a} \\
\text { Fiada }\end{array}$} \\
\hline \multirow[t]{5}{*}{$\begin{array}{c}\text { Blocos de Concreto - } \\
\text { Armadas }\end{array}$} & \multirow{5}{*}{2,00} & \multirow{5}{*}{4,18} & $\begin{array}{r}\text { Flexão } \\
(\mathrm{MPa})\end{array}$ & $\begin{array}{l}\text { Compressão } \\
(\mathrm{MPa})\end{array}$ & $\begin{array}{l}\text { Característico } \\
\text { (MPa) }\end{array}$ & $\begin{array}{l}\text { Média } \\
(\mathrm{MPa})\end{array}$ \\
\hline & & & 2,81 & 7,00 & 32,78 & 27,86 \\
\hline & & & \multicolumn{2}{|c|}{$\begin{array}{c}\text { Argamassa (MPa) - Até } \\
14^{\mathrm{a}} \mathrm{Fiada}\end{array}$} & \multicolumn{2}{|c|}{$\begin{array}{l}\text { Graute (MPa) - Até } 14^{\mathrm{a}} \\
\text { Fiada }\end{array}$} \\
\hline & & & $\begin{array}{l}\text { Flexão } \\
(\mathrm{MPa})\end{array}$ & $\begin{array}{c}\text { Compressão } \\
(\mathrm{MPa})\end{array}$ & $\begin{array}{l}\text { Característico } \\
\text { (MPa) }\end{array}$ & $\begin{array}{l}\text { Média } \\
(\mathrm{MPa})\end{array}$ \\
\hline & & & 2,64 & 6,27 & 27,33 & 23,23 \\
\hline Elemento & $\begin{array}{l}\text { Média } \\
\text { (MPa) }\end{array}$ & $\begin{array}{c}\text { Ep } \\
(\mathrm{GPa})\end{array}$ & \multicolumn{2}{|c|}{$\begin{array}{c}\text { Argamassa (MPa) - Até } \\
7^{\mathrm{a}} \text { Fiada }\end{array}$} & \multicolumn{2}{|c|}{$\begin{array}{c}\text { Graute (MPa) - Até } 7^{\mathrm{a}} \\
\text { Fiada }\end{array}$} \\
\hline \multirow[t]{5}{*}{$\begin{array}{c}\text { Blocos Cerâmicos - } \\
\text { Armadas }\end{array}$} & \multirow{5}{*}{0,32} & \multirow{5}{*}{0,94} & $\begin{array}{l}\text { Flexão } \\
(\mathrm{MPa})\end{array}$ & $\begin{array}{l}\text { Compressão } \\
(\mathrm{MPa})\end{array}$ & $\begin{array}{l}\text { Característico } \\
(\mathrm{MPa})\end{array}$ & $\begin{array}{l}\text { Média } \\
(\mathrm{MPa})\end{array}$ \\
\hline & & & 2,81 & 6,22 & 31,29 & 26,59 \\
\hline & & & \multicolumn{2}{|c|}{$\begin{array}{c}\text { Argamassa (MPa) - Até } \\
14^{\text {a Fiada }}\end{array}$} & \multicolumn{2}{|c|}{$\begin{array}{l}\text { Graute (MPa) - Até } 14^{\mathrm{a}} \\
\text { Fiada }\end{array}$} \\
\hline & & & $\begin{array}{l}\text { Flexão } \\
(\mathrm{MPa})\end{array}$ & $\begin{array}{c}\text { Compressão } \\
(\mathrm{MPa})\end{array}$ & $\begin{array}{l}\text { Característico } \\
\text { (MPa) }\end{array}$ & $\begin{array}{l}\text { Média } \\
(\mathrm{MPa})\end{array}$ \\
\hline & & & 2,86 & 6,77 & 24,4 & 20,74 \\
\hline
\end{tabular}

Tabela 7 - Relações de resistências à compressão média para os componentes e elementos

\begin{tabular}{l|c|c|c|c|c|c|c}
\hline & $\begin{array}{c}\text { Prisma } \\
\text { Oco/ } \\
\text { Bloco }\end{array}$ & $\begin{array}{c}\text { Prisma } \\
\text { Cheio/ } \\
\text { Oco }\end{array}$ & $\begin{array}{c}\text { Pequena } \\
\text { parede/ } \\
\text { Prisma } \\
\text { Oco }\end{array}$ & $\begin{array}{c}\text { Parede } \\
\text { Não } \\
\text { Armada// } \\
\text { Prisma }\end{array}$ & $\begin{array}{c}\text { Parede } \\
\text { Armada/ } \\
\text { Prisma }\end{array}$ & $\begin{array}{c}\text { Parede } \\
\text { Não } \\
\text { Armada/ } \\
\text { Pequena } \\
\text { parede }\end{array}$ & $\begin{array}{c}\text { Parede } \\
\text { Armada/ } \\
\text { Pequena } \\
\text { parede }\end{array}$ \\
\hline Concreto & 0,40 & 2,61 & 1,07 & 0,04 & 0,32 & 0,04 & 0,30 \\
Cerâmica & 0,40 & 1,69 & 0,55 & 0,01 & 0,08 & 0,02 & 0,14 \\
\hline
\end{tabular}




\section{Análise teórico-experimental}

Considerando as propriedades dos prismas medidos no programa experimental, analisam-se a seguir as previsões de ruptura das paredes de acordo com algumas normas e formulações teóricas. Ainda que em um dimensionamento seja necessária a adoção de valores característicos para garantir a segurança da construção, neste texto são utilizados valores médios como forma de prever a ruptura de cada parede, sem a adoção de nenhum coeficiente modificador da resistência ou do carregamento. Os valores da resistência de prisma medidos são 6,18 MPa e 4,05 MPa para blocos de concreto e cerâmicos respectivamente.

As paredes não armadas apresentaram valores de tensão de ruptura bem baixos, o que apenas reforça a impossibilidade de se conceberem paredes esbeltas não armadas. Por isso, a análise aqui está focada nos resultados das paredes armadas.

\section{Norma brasileira NBR 15961-1}

De acordo com NBR, considerando o valor de $\lambda$ igual a $280 / 9=31,1$, o valor de $R=\left[1-(\lambda / 40)^{3}\right]$ seria igual a 0,53 . A previsão da tensão de ruptura, tomando a área bruta como referência, seria então igual a $0,7 \cdot \mathrm{fp} \cdot \mathrm{R}$, igual a $2,31 \mathrm{MPa}$ e $1,52 \mathrm{MPa}$ para paredes de blocos de concreto e cerâmicos respectivamente.

\section{Norma americana ACI 530}

A norma norte-americana considera a área efetiva (área líquida argamassada) nos cálculos. Todas as paredes foram construídas dispondo argamassa sobre toda a face dos blocos, porém apenas no bloco cerâmico há coincidência de uma seção de um bloco sobre o outro quando se considera o deslocamento de $20 \mathrm{~cm}$ para amarração. Os cálculos a seguir levam em conta a seção de apenas dois cordões de argamassa nas faces dos blocos de concreto e toda a seção líquida dos blocos cerâmicos, somada à seção dos dois pontos de graute. Considerando os raios de giração de 31 $\mathrm{mm}$ e $29 \mathrm{~mm}$, tem-se que os índices de esbeltez de acordo com ACI são 90,3 e 96,6 (concreto e cerâmica respectivamente), próximos ao valor limite para considerar parede muito esbelta, sendo válida a Eq. 6. A área efetiva de cada parede é de $0,061 \mathrm{~m}^{2}$ e $0,051 \mathrm{~m}^{2}$ (concreto e cerâmica respectivamente). De acordo com ASTM C-1314 (AMERICAN..., 2012), para prisma com relação $\mathrm{h} / \mathrm{t}=39 / 9=4,3$, deve-se corrigir a resistência de prisma por um fator igual a 1,17. Corrigindo-se a resistência do prisma e desconsiderando-se a armadura na resistência à compressão, uma vez que essas não são contraventadas, chega-se à previsão de cargas de ruptura de $255 \mathrm{kN}$ e $135 \mathrm{kN}$, equivalentes à tensão de ruptura na área bruta igual a 2,36 $\mathrm{MPa}$ e 1,26 $\mathrm{MPa}$ (concreto e cerâmica respectivamente).

\section{Norma canadense CSA S301.1}

A normalização canadense também leva em conta a área efetiva de argamassa e tem como referência para a resistência de prisma o ensaio preconizado pelo ASTM C-1314 (AMERICAN..., 2012). Portanto, as mesmas áreas e correção de resistência de prisma são aplicadas. Os valores do momento de inércia de cada parede (área efetiva de argamassa + graute) são $6,1 \times 10^{-5}$ e $4,4 \times 10^{-5} \mathrm{~m}^{4}$ (concreto e cerâmica respectivamente). Os valores de $\mathrm{E}$ medidos nos ensaios de prisma, corrigidos para a área líquida, são 25,1 GPa e 7,7 GPa (concreto e cerâmica respectivamente). $\mathrm{O}$ valor de E pela norma canadense deve ser tomado como igual a $850 \bullet \mathrm{f}_{\mathrm{p}}$, portanto igual a $11,17 \mathrm{GPa}$ e 7,60 $\mathrm{GPa}$ (concreto e cerâmica respectivamente). Considerando que as armaduras estão posicionadas no centro do bloco e pouco contribuem para o aumento do momento de inércia da seção efetiva, o valor da rigidez EI será considerado como de alvenaria não armada, tomada igual a $E I_{e f}=$ $0,4 E_{a} I_{0}$, o que resulta valores iguais a 614 e 136 $\mathrm{kN} \cdot \mathrm{m}^{2}$ e cargas críticas $\left(\mathrm{P}_{\mathrm{cr}}\right)$ iguais a $344 \mathrm{kN}$ e 166 $\mathrm{kN}$ (concreto e cerâmica respectivamente), desprezando efeitos de fluência e coeficientes de segurança. De acordo com a prescrição da norma, deve-se levar em conta uma excentricidade mínima de $0,1 \mathrm{t}$ no topo, ou $0,1 \cdot 0,09=0,009 \mathrm{~m}$.

$\mathrm{O}$ valor do momento no centro da parede é, então, calculado pela Eq. 10, com $C_{m}=1,0$ na ausência de força lateral (Eq. 23):

$M_{d, \text { total }}=M_{d} \frac{C_{m}}{1-{ }^{P} / P_{c r}} \rightarrow M=P \cdot 0,009 \frac{1,0}{1-P / P_{c r}}$ Eq. 23

O equilíbrio de uma seção não resistente à tração com carga excêntrica só é possível quando a excentricidade coincide com a posição da linha neutra da seção. Considerando-se a seção vazada e desprezando-se a armadura colocada no centro da seção, a posição de equilíbrio é mostrada na Figura 9. A posição de equilíbrio, $r$, em função da excentricidade, e, geometricamente é definida por (Eq. 24):

$e=\frac{r(t-r)}{2\left(2 t_{f}-r\right)} \rightarrow r=$

$\left(\frac{t}{2}+e\right)-$

$\frac{1}{2} \sqrt{t^{2}+4 t e+4 e^{2}-16 e t_{f}} ;$ parar $\leq t_{f}$

$\mathrm{Ou}$

$e=r-\frac{t}{2} \rightarrow r=e+\frac{t}{2} ;$ para $r>t_{f}$

Eq. 24 
Figura 9 - Equilíbrio de uma seção vazada sujeita à força axial excêntrica

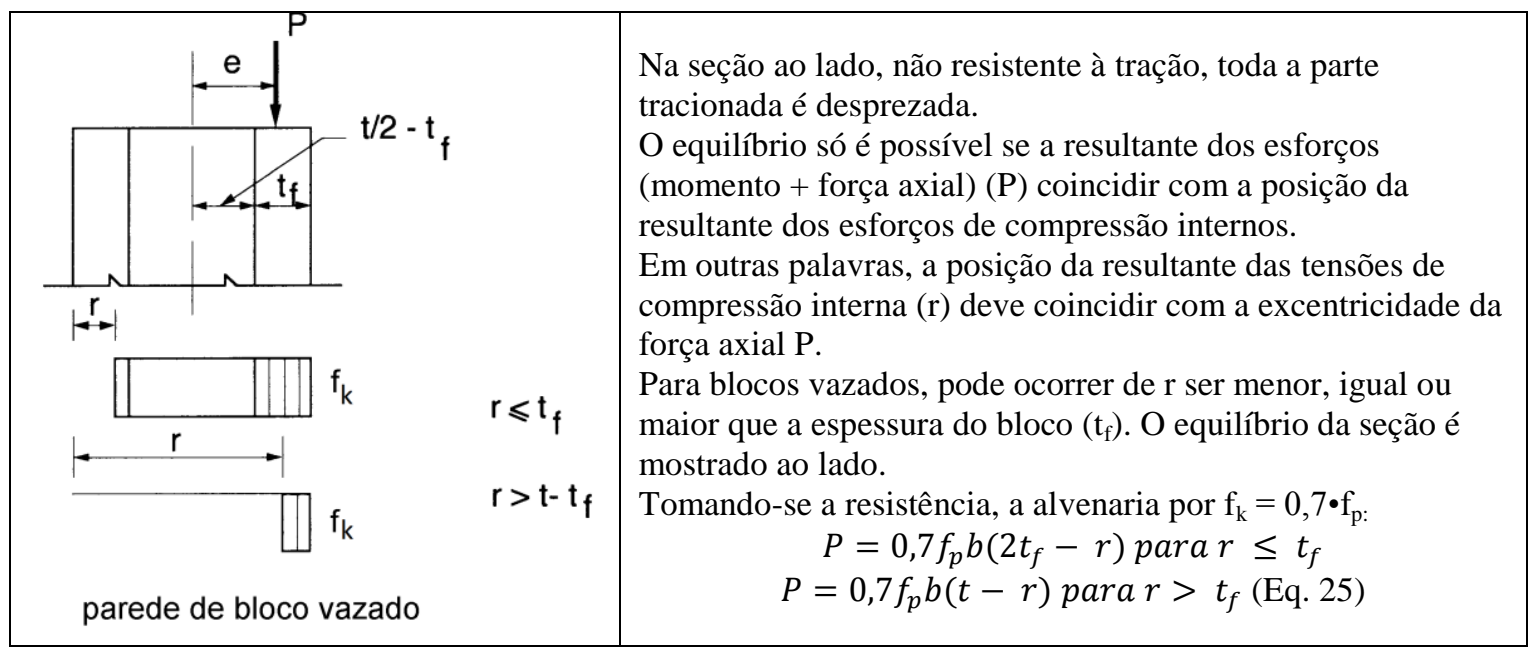

A solução é obtida de maneira iterativa:

(a) admite-se um valor da excentricidade total no meio da parede;

(b) calcula-se o valor de r com a Eq. 24;

(c) calcula-se o valor de M no meio da seção com a Eq. 23;

(d) calcula-se o valor de P com a Eq. 25; e

(e) calcula-se o valor de e=M/P; ... repete-se o processo até que os valores de e inicial e final coincidam, o que leva ao valor da carga $\mathrm{P}$ de equilíbrio.

Para o caso de bloco de concreto, admitindo que $\mathrm{r}$ $<\mathrm{t}_{\mathrm{f}}($ Eq. 26):

$e=M / P=0,009 \frac{1,0}{1-^{P} / 344} ; \mathrm{t}=0,09 \mathrm{~m} ; \mathrm{t}_{\mathrm{f}}=$ $0,018 \mathrm{~m} ; \mathrm{f}_{\mathrm{p}}=15.381 \mathrm{kN} / \mathrm{m}^{2} \quad$ Eq. 26

$\rightarrow$ Admitindo inicialmente e $=0,032 \mathrm{~m} \rightarrow \mathrm{r}=$ $0,0168 \rightarrow \mathrm{P}=248,1 \mathrm{kN} \rightarrow \mathrm{e}=0,0323 \rightarrow \mathrm{r}=$ $0,0169 \rightarrow \mathrm{P}=246,9 \mathrm{kN} \rightarrow \mathrm{e}=0,0319 \rightarrow \mathrm{r}=$ $0,0168 \rightarrow \mathrm{P}=248,6 \mathrm{kN} \rightarrow \mathrm{e}=0,0324 \rightarrow \mathrm{r}=$ $0,0169 \rightarrow \mathrm{e}=0,0318 \rightarrow$ próximo ao anterior. Observa-se que $\mathrm{r}=0,0169<\mathrm{t}_{\mathrm{f}}=0,018$; portanto, as duas faces do bloco estão comprimidas. Com esse valor de $\mathrm{P}$, a tensão de ruptura equivalente à área bruta é de 2,28 MPa.

O caso do bloco cerâmico é mais complexo, pois cada face do bloco tem duas paredes, uma de 8 $\mathrm{mm}$ e outra de $7 \mathrm{~mm}$, com espaço de $17 \mathrm{~mm}$ entre elas. A análise aqui é feita de forma aproximada, tomando-se $\mathrm{t}_{\mathrm{f}}$ igual à soma dessas três dimensões (32 mm), porém com a resistência de prisma corrigida pela razão entre a espessura real e a considerada, igual a $(7+8) /(7+17+8)=0,47$ (Eq. 27):
$e=M / P=0,009 \frac{1,0}{1-P / 166} ; \mathrm{t}=0,09 \mathrm{~m} ; \mathrm{t}_{\mathrm{f}}=$ $0,0032 \mathrm{~m} ; \mathrm{f}_{\mathrm{p}}=0,47 \cdot 10.460=492 \mathrm{kN} / \mathrm{m}^{2} \quad$ Eq. 27

$\rightarrow$ Admitindo inicialmente $\mathrm{e}=0,02 \mathrm{~m} \rightarrow \mathrm{r}=$ $0,0241 \rightarrow \mathrm{P}=16,4 \mathrm{kN} \rightarrow \mathrm{e}=0,0010 \rightarrow \mathrm{r}=$ $0,0132 \rightarrow \mathrm{P}=21,0 \mathrm{kN} \rightarrow \mathrm{e}=0,0103 \rightarrow \mathrm{r}=0,0136$ $\rightarrow \mathrm{P}=20,8 \mathrm{kN} \rightarrow \mathrm{e}=0,0103 \rightarrow$ próximo ao anterior. Observa-se que $\mathrm{r}=0,01132<\mathrm{t}_{\mathrm{f}}=0,032$; portanto, ressalvando a aproximação feita, as duas faces do bloco estão comprimidas. Com esse valor de $\mathrm{P}$, a tensão de ruptura equivalente à área bruta é de 0,19 MPa.

\section{Norma europeia BS EN 1996-1-1}

Para o caso de Eurocode 6, deve-se considerar o menor redutor calculado com a excentricidade de carga existente no topo e na base $\left(\phi_{\mathrm{i}}\right)$ ou no meio da parede $\left(\phi_{\mathrm{m}}\right)$. Como não há momentos aplicados no topo e na base, apenas $\phi_{\mathrm{m}}$ é considerado como crítico. Para o caso $\mathrm{e}_{\mathrm{mk}}$, é tomado como o mínimo especificado (Eq. 18), igual a 0,05·0,09 $=0,0045$ m. Das Eq. 17 e Eq. 16, calculam-se $\mathrm{u}=1,38$ e $\phi_{\mathrm{m}}$ $=0,349$. Considerando a resistência da parede como $0,7 \cdot f_{p}$, chega-se à previsão de tensões de ruptura iguais a 1,51 $\mathrm{MPa}$ e 0,99 $\mathrm{MPa}$ (concreto e cerâmica respectivamente). A Eq. 17 considera o valor de $E_{a}=700 f_{p}$. Outra consideração pode ser feita considerando-se a Eq. 18, com valores de E iguais a $600 f_{p}$ e $800 f_{p}$ (concreto e cerâmica respectivamente), como indicado na normalização brasileira. Com esse ajuste os valores da tensão de ruptura são estimados em 1,72 $\mathrm{MPa}$ e $0,84 \mathrm{MPa}$ (concreto e cerâmica respectivamente).

\section{Norma australiana AS 3700}

Na AS 3700 (STANDARDS..., 2001) deve-se usar a Eq. 22 para calcular a resistência, chegando-se a 
valores de tensão de ruptura iguais a 2,03 $\mathrm{MPa}$ e 1,33 $\mathrm{MPa}$ (concreto e cerâmica respectivamente).

\section{Discussão}

A Tabela 8 resume os resultados das previsões de tensão de ruptura de acordo com cada norma, em comparação com os resultados obtidos nos ensaios.

É possível observar que em todos os casos a previsão de ruptura das paredes de blocos de concreto, cuja geometria de bloco vazado é usual em todos os países, é bastante razoável por qualquer norma. A previsão das normas brasileira, americana e canadense resulta entre $15 \%$ e $18 \%$ maior que o obtido nos ensaios. Um fator favorável à norma brasileira é que essa indica prever condição birrotulada nas extremidades, mesmo na condição de vinculação laje-laje (basetopo), que ocorre na maioria das vezes (os ensaios foram feitos com condição rigorosa de articulações na base e no topo). Dessa forma, provavelmente não há grande preocupação em se utilizar esse fator simplificado, dentro do limite previsto. Devese ainda considerar que o dimensionamento é feito com valores característicos, e não médios, e inclui coeficiente de minoração da resistência da alvenaria igual a 2,0 (combinação normal). Pelo Eurocode, a carga de ruptura prevista é $25 \%$ menor que a obtida nos ensaios, sendo essa a mais conservadora das normas.

Para o caso de paredes com blocos cerâmicos de geometria complexa de blocos vazados (com paredes dos blocos também vazados), apenas a norma canadense permitiu prever uma tensão de ruptura mais próxima da verificada nos ensaios e com alguma segurança. Os resultados das demais normas são muito superiores à real tensão de ruptura e, portanto, contra a segurança.

Em todas as formulações é possível verificar que a carga de ruptura de uma parede esbelta é dependente do valor do módulo de elasticidade adotado. Em várias normas, o módulo é estimado simplesmente como 700 a 1.000 vezes a resistência do prisma, sendo esse valor subtendido na formulação (NBR, ACI, Eurocode, AS). Também é possível comentar que as formulações da maioria das normas levam em conta resultados de ensaios de blocos maciços e, portanto, não permitem levar em conta a real geometria da seção. A retirada de vazio central de um bloco maciço, tornando-o vazado, altera um pouco a relação entre momento de inércia e área da seção da parede. Usualmente se aumenta o raio de giração em blocos vazados quando comparados com blocos maciços. Apenas as prescrições da norma canadense CSA levam em conta, de forma genérica, a real seção da parede e o real valor do módulo de elasticidade. Geometrias complexas, não usuais em outros países, como parece ser o caso dos blocos cerâmicos vazados com paredes dos blocos também vazadas, podem exigir uma melhor formulação para ser possível prever a ruptura de elementos comprimidos de maior esbeltez.

\section{Conclusão}

Paredes muito esbeltas devem ser armadas, tendo sido verificadas grande instabilidade e baixíssima carga de ruptura para as paredes ensaiadas com $\mathrm{h} / \mathrm{t}=31,1$. Destaca-se ainda que o efeito da esbeltez é sensível ao módulo de elasticidade da parede. Assim, blocos de maior resistência, que levam a alvenaria de maior módulo de elasticidade, E, são mais apropriados para paredes esbeltas. É interessante ressaltar a recomendação da norma canadense que permite a construção de paredes esbeltas, porém limitando a tensão a $10 \%$ da resistência do prisma (em valores de projeto) em paredes armadas.

A partir do estudo realizado, pode-se concluir que as formulações aproximadas das normas de alvenaria não são adequadas para prever a ruptura de parede de bloco cerâmico de geometria de parede vazada. Para essa situação, apenas a formulação mais precisa da norma canadense, que leva em conta o efeito $\mathrm{P} \Delta$ e analisa a ruptura da seção como um material não resistente à tração, pôde ser aplicada com segurança.

Tabela 8 - Comparação da resistência à compressão das paredes esbeltas $(h / t=31,1)$ obtida nos ensaios com procedimentos indicados em normas

\begin{tabular}{c|c|c|c|c}
\hline \multirow{2}{*}{ Referência } & \multicolumn{2}{|c|}{ Resultado } & \multicolumn{2}{c}{ Relação norma/ensaio } \\
\cline { 2 - 5 } & Concreto & Cerâmica & Concreto & Cerâmica \\
\hline Ensaio & 2,00 & 0,32 & 1,00 & 1,00 \\
NBR 15961-1 (ABNT, 2011a) & 2,31 & 1,52 & 1,16 & 4,74 \\
ACI 530 (AMERICAN..., 2013) & 2,36 & 1,26 & 1,18 & 3,92 \\
CSA S304.1 (CANADIAN..., 2004) & 2,30 & 0,19 & 1,15 & 0,60 \\
BS EN 1996-1-1 (BRITISH..., 2005b) & 1,51 & 0,99 & 0,75 & 3,09 \\
AS 3700 (STANDARDS..., 2001) & 2,03 & 1,33 & 1,01 & 4,15 \\
\hline
\end{tabular}


No caso da parede de bloco vazado de concreto, os resultados das várias normas foram próximos, ainda que ligeiramente contra a segurança (pela norma brasileira, previsão $16 \%$ acima do medido em ensaio). Como o coeficiente de segurança e os valores característicos são aplicados no projeto, e ainda com a consideração de elemento biarticulado para parede com laje na base e topo (usualmente considerada biengastada em outras normas), entende-se que, dentro do limite de esbeltez menor que 30 , as recomendações das normas são razoáveis.

Paredes mais esbeltas e com blocos de geometrias complexas exigem procedimentos mais refinados para o cálculo, podendo ser o processo $\mathrm{P} \Delta \mathrm{e}$ a verificação da seção como não resistente à tração uma solução.

As recomendações acima podem ser incluídas na normalização brasileira para permitir o uso de paredes estruturais esbeltas.

\section{Referências}

\section{AMERICAN CONCRETE INSTITUTE. ACI}

530: building code requirements for masonry structures. Farmington Hills, 2013.

\section{AMERICAN SOCIETY FOR TESTING AND MATERIALS. ASTM C1314: standard test method for compressive strength of masonry prisms. Philadelphia, 2012.}

ASSOCIAÇÃO BRASILEIRA DE NORMAS TÉCNICAS. NBR 15270-3: componentes cerâmicos: parte 3: blocos cerâmicos para alvenaria estrutural e de vedação: método de ensaio. Rio de Janeiro, 2005.

\section{ASSOCIAÇÃO BRASILEIRA DE NORMAS}

TÉCNICAS. NBR 15961-1: alvenaria estrutural: blocos de concreto: parte 1: projeto. Rio de Janeiro, 2011a.

\section{ASSOCIAÇÃO BRASILEIRA DE NORMAS} TÉCNICAS. NBR 15961-2: alvenaria estrutural: blocos de concreto: parte 2: execução e controle de obras. Rio de Janeiro, 2011b.

ASSOCIAÇÃO BRASILEIRA DE NORMAS TÉCNICAS. NBR 15812-1: alvenaria estrutural: blocos cerâmicos: parte 1: projeto. Rio de Janeiro, 2010.

ASSOCIAÇÃO BRASILEIRA DE NORMAS TÉCNICAS. NBR 14321: paredes de alvenaria estrutural: determinação da resistência ao cisalhamento. Rio de Janeiro, 1999.
ASSOCIAÇÃO BRASILEIRA DE NORMAS TÉCNICAS. NBR 5738: concreto: procedimento para moldagem e cura de corpos de prova. Rio de Janeiro, 2008.

ASSOCIAÇÃO BRASILEIRA DE NORMAS TÉCNICAS. NBR 5739: concreto: ensaios de compressão de corpos de prova cilíndricos. Rio de Janeiro, 2007.

ASSOCIAÇÃO BRASILEIRA DE NORMAS TÉCNICAS. NBR 8949: paredes de alvenaria estrutural: ensaio à compressão simples: método de ensaio. Rio de Janeiro, 1985.

ASSOCIAÇÃO BRASILEIRA DE NORMAS

TÉCNICAS. NBR 12118: blocos vazados de concreto simples para alvenaria: métodos de ensaio. Rio de Janeiro, 2010.

\section{BRITISH STANDARD. EN 1996-1-1:}

EUROCODE 6: design of masonry structures: general rules for reinforced and unreinforced masonry structures. Bruxelas, $2005 \mathrm{~b}$.

BRITISH STANDARDS. BS 5628-1: code of practice for the use of masonry. Structural use of unreinforced masonry. London, 2005a.

CANADIAN STANDARDS ASSOCIATION. CSA S304.1-14: design of masonry structures. Toronto, 2004.

CORREA, M. R. S.; SILVA, R. M. The New Brazilian Clay Masonry Code, $1^{\text {st }}$. part: design. In: INTERNATIONAL MASONRY CONFERENCE, 8., Dresden, 2010. Proceedings... Dresden, 2010.

LOPES, G. M. Estudo Teórico e Experimental de Parede Esbeltas de Alvenaria Estrutural. São Carlos, 2014. Dissertação (Mestrado em Estruturas e Construção Civil) - Escola de Engenharia, Universidade Federal de São Carlos, São Carlos, 2014.

PARSEKIAN, G. A. Tecnologia de Produção de Alvenaria Estrutural Protendida. São Paulo, 2002. Tese (Doutorado em Engenharia Civil) Escola de Engenharia, Universidade de São Paulo, São Paulo, 2002.

PARSEKIAN, G. A.; HAMID, A. A.; DRYSDALE, R. G. Comportamento e Dimensionamento de Alvenaria Estrutural. 2. ed. São Carlos: EdUFSCar, 2013. v. 1.

STANDARDS ASSOCIATION OF AUSTRALIA. AS 3700: masonry structures. Sydney, 2001. 


\section{Guilherme Aris Parsekian}

Departamento de Engenharia Civil, Centro de Ciências Exatas e de Tecnologia | Universidade Federal de São Carlos | Rodovia Washington Luís, SP-310, Km 235, Monjolinho | São Carlos - SP - Brasil | CEP 13565-905 | Tel.: (16) 3351-9657 | E-mail: parsekian@ufscar.br

\section{Márcio Roberto Silva Corrêa}

Departamento de Estruturas, Escola de Engenharia de São Carlos | Universidade de São Paulo | Av. Carlos Botelho, 1465, Vila Pureza | São Carlos - SP - Brasil | CEP 13560-250 | Tel.: (16) 3373-9458 | E-mail: mcorrea@sc.usp.br

\section{Guilherme Martins Lopes}

Morelli Lopes Engenharia | Av. Gustavo Chiozzi, 445, Jd. Netinho Prado Jaú - SP - Brasil | CEP 17208-088 | Tel.: (14) 3621-4142 |

E-mail: eng.guilherme.lopes@gmail.com.br

\section{Isabella Cavichiolli}

Centro de Ciências Exatas e de Tecnologia | Universidade Federal de São Carlos | Tel.: (16) 3351-8260 |

E-mail: bellaa_cavichiolli@hotmail.com

Revista Ambiente Construído

Associação Nacional de Tecnologia do Ambiente Construído

Av. Osvaldo Aranha, $99-3^{\circ}$ andar, Centro

Porto Alegre - RS - Brasil

CEP $90035-190$

Telefone: +55 (51) 3308-4084

Fax: +55 (51) 3308-4054

www.seer.ufrgs.br/ambienteconstruido

E-mail: ambienteconstruido@ufrgs.br 